\title{
The long Covid effect in marketing and consumer research
}

\author{
Eleonora Di Maria ${ }^{1} \cdot$ Michele Simoni $^{2} \cdot$ Giuseppe Pedeliento $^{3} \cdot$ Marco Galvagno $^{4}$
}

Published online: 18 October 2021

C Società Italiana Marketing 2021

The Covid-19 pandemic has dramatically impacted firms and consumers (Donthu \& Gustafsson, 2020). On one hand, firms had the opportunity to establish and manage relationships with key market actors by redefining established business processes of production, distribution, and even product development. On the other one, consumers were forced to temporarily or permanently change their habits and the way they buy, shop, consume, and travel (Sheth, 2020). This new scenario, sparked by the Covid-19 pandemic, caused important implications for firms. In fact, it required them to rapidly reorganize their processes and activities to continue running their businesses (Seetharaman, 2020) and prompted new forms of product (Ebersberger \& Kuckertz, 2021) and service (Sharma et al., 2021) innovations to keep up with a new demand. Furthermore, it brought profound changes in the way firms manage relationships and communicate with their customers (Mangiò et al., 2021), and, above all, led to severe changes in consumers' behaviours (Zwanka \& Buff, 2021).

Yet, while Covid-19 is undoubtedly one of the most traumatic events humanities have faced since the end of World War II, it also determined the emergence of novel social, economic, and business challenges that attracted the attention and interest of many marketing scholars. An attention that, we note, did not run out once the hardest times of the pandemic had been overcome but, on the contrary, one which is still

Giuseppe Pedeliento

giuseppe.pedeliento@unibg.it

Eleonora Di Maria

eleonora.dimaria@unipd.it

Michele Simoni

michele.simoni@uniparthenope.it

Marco Galvagno

marco.galvagno@unict.it

1 Department of Economics and Management, University of Padova, Padua, Italy

2 Department of Management and Quantitative Studies, University of Naples "Parthenope", Naples, Italy

3 Department of Management, University of Bergamo, Bergamo, Italy

4 Department of Economics and Business, University of Catania, Catania, Italy 
particularly high even at present time, when the world is gradually moving toward recovery and partly going back to its pre-pandemic habits.

To emphasize the persistent topicality of Covid-related research in marketing study, we borrow the term "long Covid" from medical and clinical research. "Long Covid", which is a term being used to describe illnesses in people who have recovered from Covid-19 but are still reporting lasting effects of the infection (Mahase, 2020), is here used to indicate the persistence of studies that take stock of the effects that the pandemic has provided to marketing and consumer research.

As a matter of fact, a closer look at the literature to date vividly shows that in the last two years Covid-19 has become the most mainstream topic and a sort of autonomous stream of research within the broader field of marketing research. Hundreds of papers have been published from March 2020 onward and new entries pop-up every day. Hundreds of conferences and workshops have been organized, and dozens of special issues have been published or are planned to be published in the upcoming year. These include, just to name a few, the Journal of Business Research, the Journal of Product \& Brand Management, the Journal of Advertising, the International Marketing Review, the International Journal of Retail \& Distribution Management, Management Decision, Marketing Theory, and many others.

In a similar spirit, the Italian Journal of Marketing organized an online paper development workshop entitled "Covid-19 and Marketing Research in Italy" which then inspired the publication of this special issue. The workshop witnessed the participation of more than 50 authors presenting a total of 23 papers dealing with two main domains that the Italian community identified as particularly topical: "technology and innovation marketing" and "consumer behaviour".

As far as the first domain is concerned, i.e., technology and innovation marketing, recent research on the topic has devoted attention especially to assess how technology can be leveraged to help firms find new ways to cope with a market scenario that has drastically changed due to the pandemic. Among these, there is a need to propose and assess the effectiveness of untapped and renewed strategic approaches towards the market, as well as the impact of new technology-enabled business models seeking to define new value propositions and novel ways to interact with consumers and business customers (Coombes \& Nicholson, 2013; Porter \& Heppelmann, 2015). The physical distancing imposed by the Covid-19 emergency, pushed many incumbent firms to explore new strategies-rooted in the adoption of technological solutions - and to rethink their offering in a radical or innovative way (Rapaccini et al., 2020). In this view, understanding how firms approach and invest in digital technologies to draw new strategic paths and renew their value propositions-for example by turning to contemporary models of servitization-is paramount. In a scenario in which demand and supply were forced to complete isolation, and are still forced to some degrees of social distancing, the understanding of the opportunities that technologies may offer in managing customers relationships are also of primary importance.

The complete lack of physical interaction with customers that firms had to cope with throughout the hardest times of the lockdowns, decreed by a vast majority of governments of the world to counteract the virus, has led many firms to further push technological investments in order to grant sales and business continuity via 
innovative digital tools and devices (Siggelkow \& Terwiesch, 2019). On the one hand, well-established technological solutions, such as ecommerce and mobile commerce, have experienced a further boost and have attracted additional investments. With traditional brick-and-mortar stores shut down, online commerce was the only way for retailers and firms to continue their businesses and continue selling products. On the other hand, the lack of direct interaction with consumers fostered development and investments of other more recent and more technological advanced solutions, such as virtual and augmented reality (Pantano et al., 2020).

A second topic at the intersection of technological innovation and marketing, which gained traction in the last two pandemic years, is connected to innovation processes. Digital technologies may increase their role in supporting the reconfiguration of innovation processes, also in connection with manufacturing activities. 3D printing, for example, is a disruptive technology that enhances open innovation by expanding the type and the number of actors involved within the value chain, such as Fablabs and makers, and by allowing the possibility to overcome sectorial boundaries that inevitably limit the scope and width of both technological innovation and technological adoption (Anderson, 2012; Bogers et al., 2016). In this regard, marketing research is needed to provide new insights on how the pandemic has either enabled or constrained ongoing processes of open innovation, and to shed light on how the pandemic has triggered changes in firms' marketing strategies addressed to product innovation. More in general, and not just limited to the current post-pandemic world, further studies are needed to understand how the set of digital technologies that form the backbone of the fourth industrial revolution (industry 4.0)-internet of things, smart manufacturing, and new forms of automation-shape marketing processes and create new sources of competitive advantage (Iansiti \& Lakhani, 2014).

In addition to the intense debate on whether and how technologies and innovations may assist firms in overcoming the limits and the challenges posed by the global pandemic on their marketing strategies and operations, research has also deeply focused on the impact of Covid-19 on consumer behaviour (Zwanka \& Buff, 2021).

Even though past literature has previously dealt with the question of how consumers react to adverse events, such as natural disaster or terrorist attack (Cruz-Cárdenas et al., 2021), the Covid-19 pandemic has offered a unique context to study, as this adverse event differs dramatically in terms of duration and scope. While events such as natural disasters and terrorist attacks are bounded in time and space, i.e. last for a limited time and affect a limited and geographically bounded area, the pandemic has a longer timeframe (almost two years have passed since the first news about the spread of an unknown virus in China started gaining attention in Western countries), and has as a global scope. Against this background, it is important to understand the way consumers have tried to rearrange their decision processes and have modified their consumption habits. How do consumers search for information? How do they use the retrieved information? How do they interact with firms and other consumers? How do they approach branding efforts and brand communication? These and other questions attracted the interest of marketing scholars and generated an intense debate that did not spare any marketing journal. 
For example, scholars have shown that the pandemic led to changes on how consumers engage with brands on social media platforms (Mangiò et al., 2021), provided drastic modifications on planned and unplanned purchasing habits (Sheth, 2020), changed traditional schemata that consumers generally use to evaluate alternative offerings and perform a choice (Kim et al., 2021), and affected the traditional way in which consumers relate to retailers (Roggeveen \& Sethuraman, 2020).

The implications that these researches brought to light are manifold, especially if the scholars' prediction that the pandemic is destined to bring permanent consequences on marketing and consumer behaviour, comes true. The disruptive force of the pandemic was so huge that scholars and practitioners agree that new theoretical lenses and new practical competences will be needed to make and give full sense to market functioning. In a time in which the Western World is hopefully recovering after the backlash of the pandemic, research is needed to assess whether and how the pandemic has brought permanent transformations to firms' marketing strategies and tactics, as well as to assess the extent to which established firms' marketing strategies and tactics are no longer effective or are less effective than they used to be in the pre-Covid-19 era.

The six papers included in this special issue are all similar in their attempt to make sense of the transformations that the Covid-19 pandemic has implied in the marketing realm, but offer different theoretical reflections and practical implications.

Bettiol et al. (2021) shed light on how SMEs have dealt with the Covid-19 pandemic by exploiting digital technologies to reconnect with customers (26 Italian SMEs analyzed). The study found that SMEs improved the quantity and quality of interactions with customers by using web-based technologies and investing in digital contents. In particular, CRM and e-commerce solutions helped SMEs support competition and performance and, thus, overcome the emerging challenges. These findings have significant managerial implications. To be reactive to the crisis, SMEs should be technologically ready, embrace new operating methods and processes focused on customers, where the web-based technologies are not only a tool for reaching them, but also the starting point of the marketing processes itself. During crisis time, SMEs should increase the use of web-based technologies to connect, interact, and manage customers in order to satisfy their needs and take care of them.

Belvedere et al. (2021) demonstrate that the pandemic has triggered further e-commerce penetration, posing new challenges to the adoption of this sales channel. In their paper, they provide a conceptual framework capable of explaining the actions undertaken by leading companies to effectively get the most from an e-commerce strategy integrated within the overall omnichannel one. Furthermore, they identify two factors that deserve attention: main distribution channel (direct/indirect) and product value density (high/low). Through the analysis of four case studies (Luxottica, Henkel, Ikea, and Ferragamo), they showed that these factors produce different benefits and challenges that companies face when embracing e-commerce both from a marketing point of view and supply chain management one. The paper offers useful suggestions for companies on how to better frame their decisions on the adoption of e-commerce, with a newly developed degree of awareness, especially in regards to the factors that they should consider in order to get the most out of these 
initiatives, both in terms of marketing processes and supply chain ones, while still mitigating the inefficiencies possibly generated by last mile logistics.

Di Domenico et al. (2021) analyse how tweets' textual and non-textual cues affect their virality, focusing on misinformation content spread during the Covid-19 pandemic. Results suggest that misinformation included in a tweet plays an interesting role in disseminating it through the network, especially when associated with a more analytical, authentic, and confident language. Moreover, Twitter users actually read a tweet but not necessarily understand or critically evaluate it before making the decision of sharing it on the platform. This supports the role of confirmation bias in affecting individuals' susceptibility to misinformation, as the tendency to propagate contents through social media largely depends on textual cues different from the veracity of contents. In terms of managerial contribution, this study suggests that companies should continuously monitor tweets to avoid the spread of misinformation, not only inside the echo-chambers but also outside of them to avoid negative impacts on the company's reputation. Social media platforms should not only focus on the content (i.e. misinformation) but also on how it is conveyed.

Corsaro et al. (2021) studied the impact of the Covid-19 pandemic as a driver of adoption of Sales \& Marketing Automation (S\&MA) by B2B companies. Based on insights generated through a qualitative and quantitative research, they propose a conceptual model explaining the benefits and sacrifices of S\&MA. Their findings not only highlight that a mere focus on the technological side of S\&MA limits the assessment of value generation; but also underline that as different buyers have different perceptions of S\&MA solutions, such perceptions can be used by vendors to segment their market and target key customers.

Del Chiappa et al. (2021) studied the changing preferences of travellers as a result of the coping strategies adopted to protect themselves from the sanitary crisis. They found that two factors drive the destination choice: "personal protective equipment, sanitation, and physical distancing" and "outdoor and under-crowded tourism attractions and destinations". The analysis allows the definition of three groups of travellers: "all-round concerned tourists", "middle-concerned tourists", and "outdoordriven tourists", who differ from one another in terms of socio-demographics and travel-related variables. This research not only empirically shows that the ways in which travel preferences are changing are not homogenous, but it also contributes to identifying a certain number of adaptive coping mechanisms which may guide tourists' decisions during these uncertain times.

Finally, Cannavale et al. (2021) discuss social innovation potentialities connected to reverse innovation in the Covid-19 scenario, by merging two different theoretical perspectives. The authors examine the Korean case study connected to the "Drivethrough testing center" to outline how this innovation has spread beyond the socioinstitutional context of development to a broader global scale (from less developed to more advanced national Countries). The paper identifies the conditions for a positive diffusion of social innovation processes which go beyond the context of development, enriching the theoretical discussion on open innovation framework during Covid-19.

Although there is still a long way before a solid understanding on how the pandemic has impacted marketing research and practice can be reached, the papers 
included in this special issue are a step toward the achievement of said understanding and open new and untapped opportunities for further research.

\section{References}

Anderson, C. (2012). Makers-The new industrial revolution. Crown Business Books.

Belvedere, V., Martinelli, E. M., \& Tunisini, A. (2021). Getting the most from E-commerce in the context of omnichannel strategies. Italian Journal of Marketing. https://doi.org/10.1007/ s43039-021-00037-6

Bettiol, M., Capestro, M., Di Maria, E., \& Micelli, S. (2021). Reacting to the COVID-19 pandemic through digital connectivity with customers: The Italian experience. Italian Journal of Marketing. https://doi.org/10.1007/s43039-021-00031-y

Bogers, M., Hadar, R., \& Bilberg, A. (2016). Additive manufacturing for consumer-centric business models: Implications for supply chains in consumer goods manufacturing. Technological Forecasting and Social Change, 102, 225-239.

Cannavale, C., Claudio, L., \& Simoni, M. (2021). How social innovations spread globally through the process of reverse innovation: A case-study from South Korea. Italian Journal of Marketing. https:// doi.org/10.1007/s43039-021-00027-8

Coombes, P. H., \& Nicholson, J. D. (2013). Business models and their relationship with marketing: A systematic literature review. Industrial Marketing Management, 42(5), 656-664. https://doi.org/10. 1016/j.indmarman.2013.05.005

Corsaro, D., Maggioni, I., \& Olivieri, M. (2021). Sales and marketing automation in the post-Covid-19 scenario: Value drivers in B2B relationships. Italian Journal of Marketing. https://doi.org/10.1007/ s43039-021-00024-X

Cruz-Cárdenas, J., Zabelina, E., Guadalupe-Lanas, J., Palacio-Fierro, A., \& Ramos-Galarza, C. (2021). COVID-19, consumer behavior, technology, and society: A literature review and bibliometric analysis. Technological Forecasting and Social Change. https://doi.org/10.1016/j.techfore.2021.121179

Del Chiappa, G., Bregoli, I., \& Atzeni, M. (2021). Uncovering knowledge on travel behaviour during COVID-19: A convergent parallel mixed-methods study in the context of Italy. Italian Journal of Marketing. https://doi.org/10.1007/s43039-021-00036-7

Di Domenico, G., Tuan, A., \& Visentin, M. (2021). Linguistic drivers of misinformation diffusion on social media during the COVID-19 pandemic. Italian Journal of Marketing. https://doi.org/10.1007/ s43039-021-00026-9

Donthu, N., \& Gustafsson, A. (2020). Effects of COVID-19 on business and research. Journal of Business Research, 117, 284-289.

Ebersberger, B., \& Kuckertz, A. (2021). Hop to it! The impact of organization type on innovation response time to the COVID-19 crisis. Journal of Business Research, 124, 126-135.

Iansiti, M., \& Lakhani, K. R. (2014). Digital ubiquity: How connections, sensors, and data are revolutionizing business. Harvard Business Review, 92, 19.

Kim, J., Yang, K., Min, J., \& White, B. (2021). Hope, fear, and consumer behavioral change amid COVID-19: Application of protection motivation theory. International Journal of Consumer Studies. https://doi.org/10.1111/ijcs.12700

Mahase, E. (2020). Covid-19: What do we know about 'long Covid'? BMJ, 370, m2815. https://doi.org/ 10.1136/bmj.m2815

Mangiò, F., Pedeliento, G., \& Andreini, D. (2021). Branding rhetoric in times of a global pandemic: A text-mining analysis. Journal of Advertising, 50(3), 240-252.

Pantano, E., Pizzi, G., Scarpi, D., \& Dennis, C. (2020). Competing during a pandemic? Retailers' ups and downs during the COVID-19 outbreak. Journal of Business Research, 116, 209-213.

Porter, M. E., \& Heppelmann, J. E. (2015). How smart, connected products are transforming companies. Harvard Business Review, 114, 96-112.

Rapaccini, M., Saccani, N., Kowalkowski, C., Paiola, M., \& Adrodegari, F. (2020). Navigating disruptive crises through service-led growth: The impact of COVID-19 on Italian manufacturing firms. Industrial Marketing Management, 88(May), 225-237. 
Roggeveen, A. L., \& Sethuraman, R. (2020). How the COVID-19 pandemic may change the world of retailing. Journal of Retailing, 96(2), 169-171.

Seetharaman, P. (2020). Business models shifts: Impact of Covid-19. International Journal of Information Management, 54, 102173.

Sharma, A., Shin, H., Santa-María, M. J., \& Nicolau, J. L. (2021). Hotels' COVID-19 innovation and performance. Annals of Tourism Research, 88, 103180.

Sheth, J. (2020). Impact of Covid-19 on consumer behavior: Will the old habits return or die? Journal of Business Research, 117, 280-283. https://doi.org/10.1016/j.jbusres.2020.05.059

Siggelkow, N., \& Terwiesch, C. (2019). Connected strategy: Building continuous customer relationships for competitive advantage. Harvard Business School Press.

Zwanka, R. J., \& Buff, C. (2021). COVID-19 generation: A conceptual framework of the consumer behavioral shifts to be caused by the COVID-19 pandemic. Journal of International Consumer Marketing, 33(1), 58-67.

Publisher's Note Springer Nature remains neutral with regard to jurisdictional claims in published maps and institutional affiliations. 